\title{
Erratum to: Cervical cancer screening of underserved women in the United States: results from the National Breast and Cervical Cancer Early Detection Program, 1997-2012
}

\author{
Florence K. L. Tangka ${ }^{1}$. David H. Howard ${ }^{2} \cdot$ Janet Royalty $^{1}$ - Lucinda P. Dalzell ${ }^{3}$ • \\ Jacqueline Miller $^{1} \cdot$ Brett J. O'Hara $^{3} \cdot$ Susan A. Sabatino ${ }^{1} \cdot$ Kristy Joseph $^{4}$ • \\ Kristy Kenney ${ }^{1} \cdot$ Gery P. Guy Jr. ${ }^{1} \cdot$ Ingrid J. Hall $^{1}$
}

Published online: 1 May 2015

(c) Springer International Publishing Switzerland 2015

\section{Erratum to: Cancer Causes Control DOI 10.1007/s10552-015-0524-5}

In the original publication of the article, references $7,8,12$, and 31 have not been cited properly. The corrected references are given below.

\section{References}

7. Howard D, Tangka FKL, Royalty J, Danzell LP, Miller J, O’Hara B, Joseph K, Kenney K, Guy G, Hall IJ (2015) Breast cancer screening of underserved women in the United States: results from the National Breast and Cervical Cancer Early Detection Program, 1998-2012. Cancer Causes Control. doi:10.1007/ s10552-015-0553-0

8. Lantz P, Mullen J (2015) The National Breast and Cervical Cancer Early Detection Program: 25 years of public health service to low-income women. doi:10.1007/s10552-015-0565-9

12. Dalzell LP, Tangka FKL, Powers DS, Holmes O'HaraBJ, Kristy J, Janet R (2015) Data sources to identify low income, uninsured populations: application to public health-National Breast and Cervical Early Detection Program. Cancer Causes Control. doi:10.1007/s10552-015-0571-y

31. Subramanian S, Tangka FKL, Ekwueme DU, Trogdon J, Crouse W, Royalty J (2015) Explaining variation across grantees in breast and cervical cancer screening proportions in the NBCCEDP. doi:10.1007/s10552-015-0569-5

The online version of the original article can be found under doi:10. 1007/s10552-015-0524-5.

Florence K. L. Tangka

FTangka@cdc.gov

1 Division of Cancer Prevention and Control, Centers for Disease Control and Prevention (CDC), 4770 Buford Highway NE, Mailstop F-76, Atlanta, GA 30341-3717, USA

2 Department of Health Policy and Management, Emory University, 1518 Clifton Road NE, Atlanta, GA 30322, USA

3 Social, Economics and Household Statistics Division, US Census Bureau, Washington, DC 20233-8510, USA

4 Division of Global Health Protection, Center for Global Health, CDC, 4770 Buford Highway NE, Mailstop E-93, Atlanta, GA 30329, USA 